\title{
RATES OF FIXATION BY LIGHTNING OF CARBON AND NITROGEN IN POSSIBLE PRIMITIVE ATMOSPHERES
}

\author{
W. L. CHAMEIDES \\ School of Geophysical Sciences, Georgia Institute of Technology, Atlanta, Georgia, U.S.A. \\ and \\ J. C. G. WALKER \\ Space Physics Research Laboratory, University of Michigan, Ann Arbor, Michigan, U.S.A.
}

(Received 2 February, 1981; in revised form 21 May, 1981)

\begin{abstract}
A thermochemical-hydrodynamic model of the production of trace species by electrical discharges has been used to estimate the rates of fixation of $\mathrm{C}$ and $\mathrm{N}$ by lightning in the primitive atmosphere. Calculations for various possible mixtures of $\mathrm{CH}_{4}, \mathrm{CO}_{2}, \mathrm{CO}, \mathrm{N}_{2}, \mathrm{H}_{2}$, and $\mathrm{H}_{2} \mathrm{O}$ reveal that the prime species produced were probably $\mathrm{HCN}$ and $\mathrm{NO}$ and that the key parameter determining the rates of fixation was the ratio of $\mathrm{C}$ atoms to $\mathrm{O}$ atoms in the atmosphere. Atmospheres with $\mathrm{C}$ more abundant than $\mathrm{O}$ have large $\mathrm{HCN}$ fixation rates, in excess of $10^{17}$ molecules $\mathrm{J}^{-1}$, but small $\mathrm{NO}$ yields. However, when $\mathrm{O}$ is more abundant than $\mathrm{C}$, the NO fixation rate approaches $10^{17}$ molecules $\mathrm{J}^{-1}$ while the $\mathrm{HCN}$ yield is small. The implications for the evolution of life are discussed.
\end{abstract}

\section{Introduction}

While it has been demonstrated that naturally occurring abiotic processes could have caused the synthesis of the organic molecules that were the precursors of terrestrial life, there is little quantitative knowledge of the possible rates of abiotic synthesis on the primitive Earth. However, unless the Earth originated with an abundant store of preformed organic material or accreted large amounts of organic material from meteorites, the rate of abiotic production of organics from atmospheric gases must have exerted a controlling infuence on chemical and early biological evolution and possibly also on the composition of the primitive atmosphere. Thus, without quantitative estimates of the rate of organic synthesis it is difficult to test the viability of various theories for the evolution of life over the range of possible conditions for the pre-biologic atmosphere, given the time constraints implied by the geologic and fossil records. Furthermore, the lack of quantitative information on the organic synthesis rate precludes the construction of self-consistent models of the composition of the primitive atmosphere, models which include the removal of atmospheric species due to the synthesis of organics. Similarly, there is a need for extimates of the nitrogen fixation rate by high temperature abiotic processes under a variety of atmospheric conditions to improve our understanding of the pre-biologic nitrogen cycle and the evolution of nitrate respiration, and to provide input data for models of nitrogen in the primitive atmosphere.

For at least one frequently invoked source of organic molecules and fixed nitrogen, lightning [1], it is now possible to estimate, with reasonable accuracy, the productivity in terms of fixed carbon and nitrogen for a range of assumptions concerning the primitive atmosphere. The method involves the use of a hydrodynamic-chemical model which has compared favorably with laboratory discharge experiments, as dis- 
cussed in the following section. The results depend upon the gross composition of the ambient atmosphere, and there is a diversity of opinion concerning the abundance of hydrogen and the oxidation state of carbon in the primitive atmosphere [34]. Miller and Urey [1] and many other students of chemical evolution favor a highly reducing prebiological atmosphere, containing abundant hydrogen, methane, and ammonia. Abelson [2] has argued for a weakly reducing atmosphere with carbon monoxide the dominant carbon compound. Walker [3] has advocated an atmosphere even less strongly reducing, with carbon present mainly as carbon dioxide. For our present calculations we need not choose between these possibilities; the range of atmospheres we examine embraces all of these compositions. Thus not only are our results applicable to a wide range of assumptions concerning the pre-biologic atmosphere, but they help identify the atmospheric parameters which are most critical to determining the rate of carbon and nitrogen fixation by lightning. While we limit our discussion to atmospheres with surface pressures of about 1 bar, our results are not strongly sensitive to total pressure [4].

\section{Calculation of Production Rates}

The chemical effects of lightning on the contemporary atmosphere have been extensively studied in recent years in connection with the production of trace species [4-11]. The trace species production process in linear discharges, similar to the Zel'dovich mechanism [12] for the production of NO in point explosions, has been discussed by Chameides [4], who found close agreement between calculated yields of $\mathrm{NO}, \mathrm{CO}$, and $\mathrm{N}_{2} \mathrm{O}$ and measurements in laboratory discharges $[7,10,11]$ (see Table I). The lightning bolt and associated shock wave produce a cylinder of very hot air within which chemical reactions between atmospheric gases proceed rapidly to equilibrium. The composition at equilibrium is a strongly varying function of temperature. As the air cools, mainly by expansion, the rates of reaction decrease until they become too slow to maintain the concentration of a given molecule at the equilibrium value appropriate to the temperature. The temperature at which the concentration of a given species departs from equilibrium is called the 'freeze out' temperature for that constituent because the mixing ratio corresponding to equilibrium at that temperature becomes frozen into the gas. The air temperature near the lightning bolt initially rises to values much greater than the freeze out temperature.

The freeze out temperature, $T_{F}$, is approximately determined by the relationship

$$
\tau_{T}\left(T_{F}\right)=\tau_{x}\left(T_{F}\right)
$$

where $\tau_{T}$ is the characteristic cooling time of the shock wave and $\tau_{x}$ is the chemical lifetime of species $X$. When $T>T_{F}$, then $\tau_{x}<\tau_{T}$ and the chemical reactions are sufficiently rapid to keep $X$ in thermochemical equilibrium. However, for $T<T_{F}, \tau_{x}$ $>\tau_{T}$ and chemical reactions are too slow to adjust to the rapidly decreasing $T ; X$, therefore, 'freezes out' with mixing ratio $f_{x}^{\circ}\left(T_{F}(X)\right)$. While a lower abundance of $X$ is 
TABLE I

Comparison between calculated and measured yields in electrical discharges. $E_{0}=10^{4}-10^{6} \mathrm{~J} \mathrm{~m}{ }^{-1}$.

\begin{tabular}{lllll}
\hline Species & $\begin{array}{l}P \text { calculated } \\
\left(\text { molecules } J^{-1}\right)\end{array}$ & Reference & $\begin{array}{l}P \text { measured } \\
\left(\text { molecules } J^{-1}\right)\end{array}$ & Reference \\
\hline Earth: & & & & \\
$\mathrm{NO}$ & $(6-17) \times 10^{16}$ & {$[4]$} & $(6-16) \times 10^{16}$ & {$[6,7]$} \\
$\mathrm{CO}$ & $(0.5-50) \times 10^{13}$ & {$[10]$} & $1 \times 10^{14}$ & {$[11]$} \\
$\mathrm{N}_{2} \mathrm{O}$ & $(3-13) \times 10^{12}$ & {$[11]$} & $4 \times 10^{12}$ & {$[11]$} \\
\hline
\end{tabular}

favored thermodynamically at low $T$, the kinetics are too slow for readjustment. $P$, the net yield of $X$ due to this process, is approximated by

$$
P(X)=\frac{f_{x}^{\circ}\left(T_{F}\right) M\left(E_{0}, T_{F}(X)\right)}{E_{0}}\left(\text { molecules } \mathrm{J}^{-1}\right) \text {, }
$$

where $M$ is the number of molecules per meter heated to or above $T_{F}$ in the region where $X$ is being produced, and $E_{0}$ is the discharge energy (in $\mathrm{J} \mathrm{m}^{-1}$ ). Generally, $T_{F}$ is between 1000 and $5000 \mathrm{~K}$. The rate of fixation is then given by the product of $P$ times the global rate of energy discharge by lightning.

To determine $\tau_{T}$ and $M$ we adopt the hydrodynamic, differential equations of Lin [13], which approximately simulate a strong, cylindrical shock wave produced by an instantaneous linear discharge of energy. Note that Lin's equations do not directly couple the vibrational, rotational, and chemical modes of energy transfer; however, by carrying out the calculation with $\gamma$, the specific heat ratio, varying from 1.4 to 1.25 , appropriate for temperatures from $3000 \mathrm{~K}$ to $5500 \mathrm{~K}$ [14], we are able to estimate the limiting values for $\tau_{T}$ and $M$. Similarly, Lin's equations indicate that, for the temperatures of interest, the ratio $A=\rho / \rho_{0}$ (where $\rho$ is the mass density within the heated air and $\rho_{0}=1.2 \mathrm{~kg} \mathrm{~m}^{-3}$ is the ambient mass density) varies from 1 to 10 ; we therefore determine $\tau_{x}$ and $f_{x}^{\circ}$ for $A=1$ and $A=10$ as limiting values as well. Solution of Lin's equations $[13,4]$ for $1.25 \leq \gamma \leq 1.4$ yields

$$
\left.\tau_{T}\left(T_{F}\right) \approx\left(\frac{1}{T^{\prime}} \frac{\mathrm{d} T^{\prime}}{\mathrm{d} \bar{t}}\right)^{-1}\right|_{T^{\prime}=T_{F}}=\left(6.2 \times 10^{-5} \text { to } 1.1 \times 10^{-4}\right) \frac{E_{0}^{\frac{1}{2}}}{T_{F}}[\mathrm{~s}],
$$

where $T^{\prime}$ is the temperature at the shock front. Thus, for lightning with $E_{0}$ of about $10^{5} \mathrm{~J} \mathrm{~m}^{-1}[15], \tau_{T}$ is about $10^{-6}-10^{-5} \mathrm{~s}$ for $T_{F}$ of $2000-5000 \mathrm{~K}$.

Values of $\tau_{\mathrm{HCN}}(T)$ and $\tau_{\mathrm{NO}}(T)$ were determined from the rates of the following reactions: $\mathrm{HCN}+\mathrm{M} \rightarrow \mathrm{H}+\mathrm{CN}+\mathrm{M}, \mathrm{HCN}+\mathrm{H} \rightarrow \mathrm{H}_{2}+\mathrm{CN}, \mathrm{NO}+\mathrm{N} \rightarrow \mathrm{N}_{2}+$ $\mathrm{O}, \mathrm{NO}+\mathrm{O} \rightarrow \mathrm{N}+\mathrm{O}_{2}, \mathrm{NO}+\mathrm{H} \rightarrow \mathrm{N}+\mathrm{OH}$, and $\mathrm{NO}+\mathrm{NO} \rightarrow \mathrm{N}_{2}+\mathrm{O}_{2}$ [16-18] with the concentrations of the appropriate species taken from the thermochemical equilibrium calculations, as described in the following section. We find that for $E_{0}=$ $10^{5} \mathrm{~J} \mathrm{~m}^{-1}, T_{F}$ for $\mathrm{HCN}$ is about $2000-2500 \mathrm{~K}$ and for $\mathrm{NO}$ about $3000-3500 \mathrm{~K}$ [4], depending upon the exact atmospheric composition and the value of $A$. (The vari- 
ation of $T_{F}$ with $E_{0}$ has been discussed by Chameides [4]. As $E_{0}$ increases, the shocked air cools more slowly due to a smaller surface-to-volume ratio and $T_{F}$ therefore decreases. While NO freezes out at about $2000 \mathrm{~K}$ for discharges of $10^{15}-10^{16} \mathrm{~J} \mathrm{~m}^{-1}$, $T_{F}$ (NO) in shocks from lightning with energies of about $10^{5} \mathrm{~J} \mathrm{~m}^{-1}$ is generally around $3000-3500 \mathrm{~K}$.)

For $1.25 \leq \gamma \leq 1.4$, we find from Lin's equations $[13,4]$

$$
\begin{aligned}
& M\left(T_{F}, E_{0}\right)=\pi R^{2}\left(T_{F}, E_{0}\right) n_{M}^{\circ}=(3.68 \text { to } 8.51) \times \\
& \times 10^{21} \frac{E_{0}}{T_{F}} \text { [molecules } \mathrm{m}^{-1} \text { ] }
\end{aligned}
$$

where $R$ is the shock front radius when $T^{\prime}=T_{F}$ for energy $E_{0}$ and $n_{M}^{\circ}$ is the ambient number density. Note that since $R^{2} \propto 1 / n_{M}^{\circ}, M$ is not directly dependent upon ambient pressure or density, Thus, substituting (4) into (1) we obtain

$$
P=\left[3.68\left(f_{x}^{\circ} / T_{F}(X)\right)_{\min } \text { to } 8.51\left(f_{x}^{\circ} / T_{F}(X)\right)_{\max }\right] \times 10^{21} \text { molecules } \mathrm{J}^{-1} \text {, }
$$

where the $\left(f_{x}^{\circ} / T_{F}\right)_{\min }$ and $\left(f_{x}^{\circ} / T_{F}\right)_{\max }$ represent the minimum and maximum value of $f_{x}^{0} / T_{F}$, respectively, obtained by varying $A$ from 1 to 10 . In general, increasing $A$ from 1 to 10 led to a larger value of $f_{\mathrm{HCN}}^{\circ} / T_{F}(\mathrm{HCN})$, and a smaller value of $f_{\mathrm{No}}^{\circ} / T_{F}(\mathrm{NO})$.

Note that $P$ is not directly dependent upon $E_{0}$, but is weakly coupled to $E_{0}$ through the variation of $\tau_{T}$ and thus $T_{F}$ upon $E_{0}$ [4]. Furthermore, for very weak discharges with small $E_{0}\left(\lesssim 1 \mathrm{~J} \mathrm{~m}^{-1}\right), \tau_{T}$ can become quite small, raising the possibility that over the major portion of the shock chemical equilibrium may never be attained, leading to yields which may be quite different from those obtained with more energetic discharges. Because of this coupling between $E_{0}$ and $P$, laboratory experiments cannot produce quantitative information on yields from lightning unless they reproduce lightning values for $E_{0}$. In particular, note that the results from weak laboratory sparks can be quite misleading depending upon the particular chemical system. In our calculations we adopt an $E_{0}$ of $10^{5} \mathrm{~J} \mathrm{~m}^{-1}$ and our results are thus applicable to lightning strokes with energies varying from $10^{4}$ to $10^{6} \mathrm{~J} \mathrm{~m}^{-1}$, similar to present-day strokes [15].

While the above method contains many simplifying assumptions, comparison with experimental discharges of the appropriate $E_{0}$ indicates encouraging agreement between theory and experiment for the yields of $\mathrm{NO}, \mathrm{N}_{2} \mathrm{O}$, and $\mathrm{CO}$ (see Table I). This procedure should also, therefore, be reasonably accurate for studies of discharge yields in the primitive atmosphere. What makes the above calculation tractable for a wide range of primitive atmospheres is the fact that, for large discharges, the bulk of the high temperature air as it approaches $T_{F}$ is in chemical equilibrium. Thus, its composition and the kinetic factors that determine $T_{F}$ do not depend on the detailed properties of the ambient atmosphere but only on the gross composition expressed as atomic ratios. In the next section we briefly describe the chemical equilibrium calculations. 


\section{Chemical Equilibrium in High Temperature Air}

The equilibrium concentrations of $\mathrm{HCN}, \mathrm{NO}, \mathrm{N}, \mathrm{N}_{2}, \mathrm{NH}_{y}(y=1,2,3), \mathrm{NO}_{3}, \mathrm{O}, \mathrm{O}_{2}$, $\mathrm{O}_{3}, \mathrm{H}, \mathrm{H}_{2} \mathrm{O}, \mathrm{H}_{2}, \mathrm{OH}, \mathrm{HO}_{2}, \mathrm{CO}, \mathrm{CO}_{2}, \mathrm{CH}_{y}(y=1,2,3,4)$, and $\mathrm{HNO}$ were calculated as functions of temperature and background atmospheric composition using thermochemical data from the JANAF tables. [19] Figure 1a illustrates results over the temperature range of interest in an atmosphere composed of 0.9 bar $\mathrm{N}_{2}, 0.04$ bar $\mathrm{CO}_{2}$, and 0.04 bar $\mathrm{H}_{2}$. The figure shows that both $\mathrm{CO}_{2}$ and $\mathrm{H}_{2} \mathrm{O}$ dissociate as temperature is increased, while molecular nitrogen and carbon monoxide are both stable. The most abundant form of reduced carbon is HCN. Figure $1 \mathrm{~b}$ shows the same features in a more highly reduced atmosphere with $\mathrm{CO}_{2}$ and $\mathrm{H}_{2}$ replaced by 0.025 bar $\mathrm{CO}$ and 0.03 bar $\mathrm{CH}_{4}$. It is evident that we must concentrate on $\mathrm{HCN}$, and in fact a
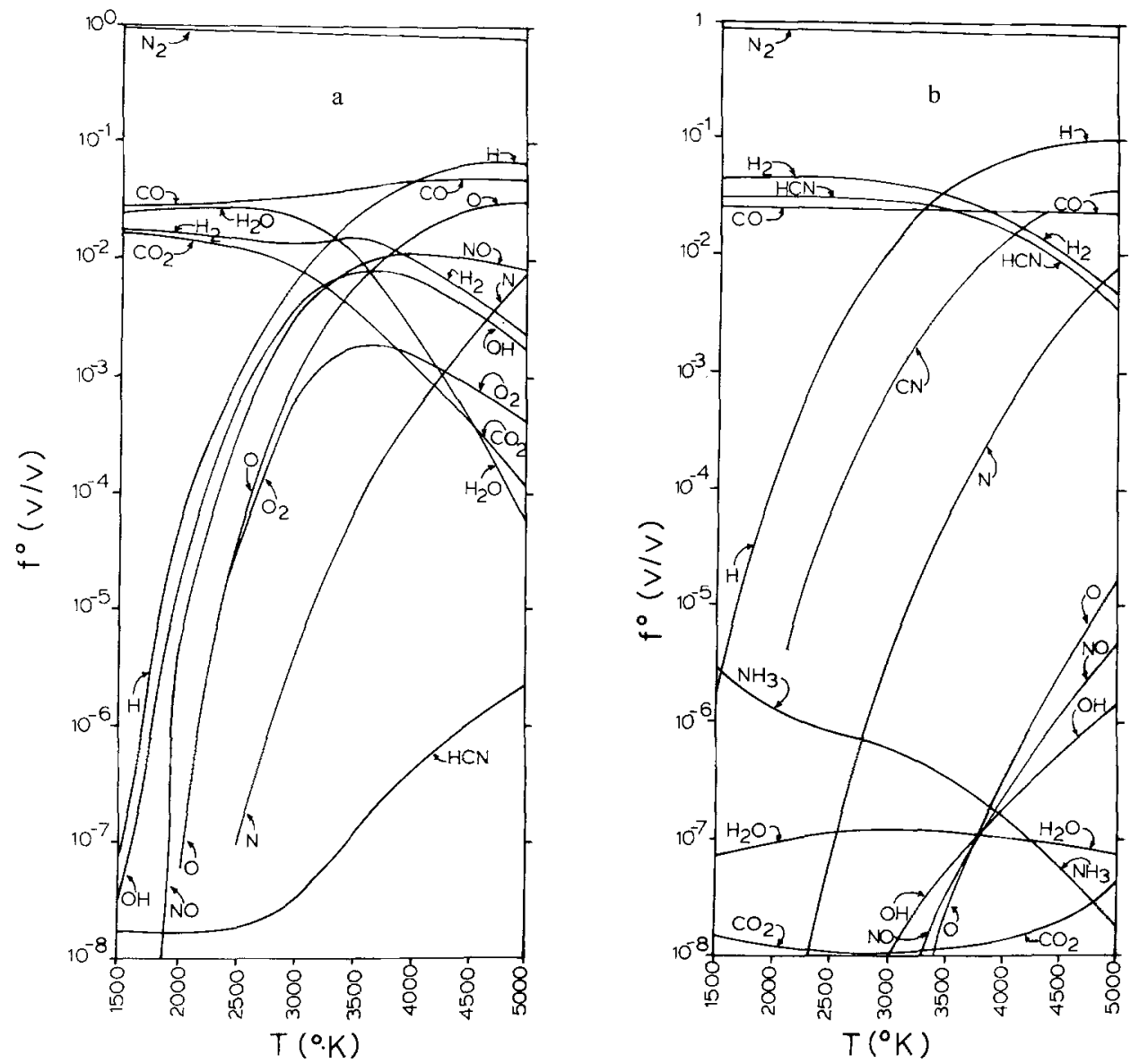

Fig. 1. The thermochemical, equilibrium volume mixing ratios, $f^{\circ}$, of various species as functions of temperature, $T$, for a mass density of $1.2 \mathrm{~kg} \mathrm{~m}^{-3}$. The ambiet composition at low temperatures is for $1 \mathrm{a}$ : $p\left(\mathrm{~N}_{2}\right)=0.9$ bar, $p\left(\mathrm{CO}_{2}\right)=0.04$ bar, $p\left(\mathrm{H}_{2}{ }^{\prime}=0.04\right.$ bar; and for 1b: $p\left(\mathrm{~N}_{2}\right)=0.9$ bar, $p(\mathrm{CO})=0.025$ bar, and $p\left(\mathrm{CH}_{4}\right)=0.03$ bar. 
number of studies have shown the suitability of $\mathrm{HCN}$ as a precursor molecule in chemical evolution [1, 2, 20-22]. For the atmospheres we have considered, which contain $\mathrm{N}$ and $\mathrm{O}$, as well as $\mathrm{C}$ and $\mathrm{H}$, hydrocarbons such as $\mathrm{C}_{2} \mathrm{H}_{2}$ are so unstable at high temperatures as to lie off the bottoms of the figures and thus there is virtually no direct production of hydrocarbons.

\section{Results}

We explore the dependence on atmospheric composition of the production rates of $\mathrm{HCN}$ and $\mathrm{NO}$ by initially holding the $\mathrm{N}_{2}$ partial pressure fixed and varying the partial pressures of $\mathrm{H}_{2}, \mathrm{H}_{2} \mathrm{O}, \mathrm{CO}, \mathrm{CO}_{2}$, and $\mathrm{CH}_{4}$ in such a way as to conserve the total number of atoms in the mixture. (We discuss later the effects of varying $\mathrm{N}_{2}$.) Since results under these conditions depend only on the ratio of $\mathrm{H}$ to $\mathrm{C}$ to $\mathrm{O}$, the composition of any mixture is adequately represented by a point on a triangle (a ternary diagram) in which the apexes represent, respectively, all $\mathrm{H}$, all $\mathrm{C}$, and all $\mathrm{O}$ (added to $\mathrm{N}_{2}$ ). Contour lines of constant production rate drawn on such a diagram show at a glance how production varies with composition. All of our results are for atmospheres constrained by

where

$$
\mathrm{N}+\mathrm{C}+\mathrm{H}+\mathrm{O}=2 \text { bar, }
$$

$$
\begin{aligned}
& \mathrm{N}=2 p\left(\mathrm{~N}_{2}\right) \\
& \mathrm{C}=p(\mathrm{CO})+p\left(\mathrm{CO}_{2}\right)+p\left(\mathrm{CH}_{4}\right) \\
& \mathrm{H}=2 p\left(\mathrm{H}_{2}\right)+2 p\left(\mathrm{H}_{2} \mathrm{O}\right)+4 p\left(\mathrm{CH}_{4}\right) \\
& \mathrm{O}=p(\mathrm{CO})+p\left(\mathrm{H}_{2} \mathrm{O}\right)+2 p\left(\mathrm{CO}_{2}\right)
\end{aligned}
$$

and $p(X)$ is the partial pressure in bars of constituent $X$. Equilibrium concentrations as functions of temperature for two atmospheres satisfying this constraint were shown in Figure 1.

Figure 2 compares contours of the logarithm of production rate in molecules $\mathrm{J}^{-1}$ for $\mathrm{HCN}$ and $\mathrm{NO}$ for atmospheres with $\mathrm{N}_{2}$ partial pressure equal to 0.9 bar. As discussed above, a variety of considerations introduce uncertainties in our results of a factor of 3 to 6 . To avoid confusion we plot just the upper bound of the estimated production rates in Figure 2.

The result most immediately apparent in Figure 2 is that production rates of HCN and $\mathrm{NO}$ vary little with the hydrogen content of the atmosphere but depend critically on the ratio of $\mathrm{C}$ to $\mathrm{O}$ (i.e., the contours are nearly vertical). There is, in fact, an inverse relationship between $\mathrm{HCN}$ and NO production. The former is favored when $\mathrm{C}$ exceeds $\mathrm{O}$, but the latter when $\mathrm{O}$ exceeds $\mathrm{C}$. This behaviour can be readily understood in terms of the stability of $\mathrm{CO}$ at high temperatures and the instability of $\mathrm{CH}_{4}$ and $\mathrm{H}_{2} \mathrm{O}$. In an atmosphere with $\mathrm{O}>\mathrm{C}$, for example one rich in $\mathrm{CO}_{2}$, most $\mathrm{C}$ is bound to $\mathrm{O}$, leaving little opportunity for $\mathrm{HCN}$ to form, but allowing excess $\mathrm{O}$ to combine with $\mathrm{N}$ to yield $\mathrm{NO}$. In the reverse situation, say a $\mathrm{CH}_{4}$ atmosphere with a 

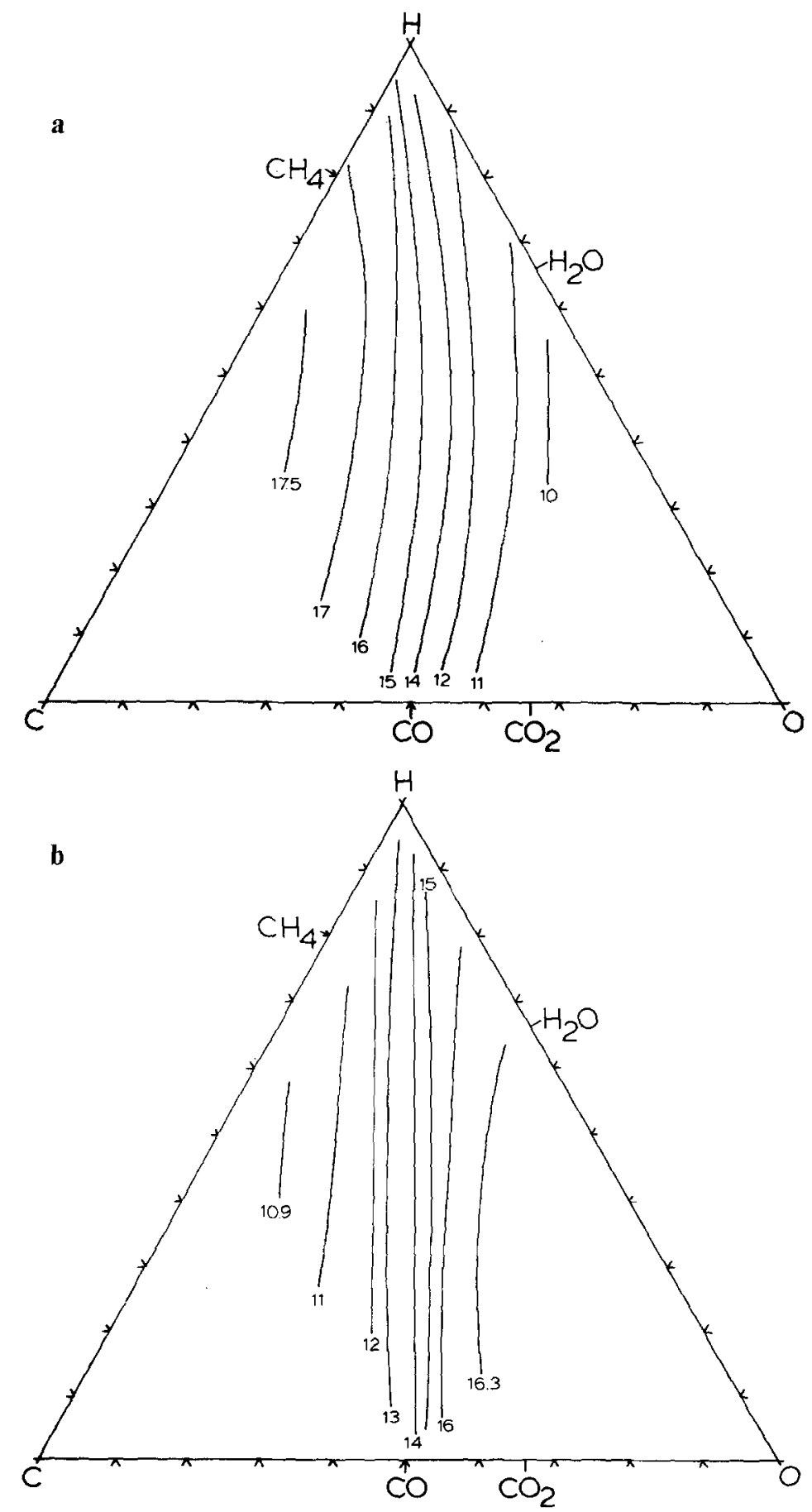

Fig. 2. Ternary diagrams of the contours of maximum yields of $\mathrm{HCN}$ (in 2a) and NO (in 2b) in discharges with $E_{0}=10^{5} \mathrm{~J} \mathrm{~m}^{-1}, p\left(\mathrm{~N}_{2}\right)=0.9$ bar, and $\mathrm{H}, \mathrm{C}$, and $\mathrm{O}$ varied in such a way that $\mathrm{N}+\mathrm{H}+\mathrm{C}+\mathrm{O}=2$ bar. The apexes labelled $\mathrm{H}, \mathrm{C}$, and $\mathrm{O}$ represent armospheres of all $\mathrm{N}$ and $\mathrm{H}, \mathrm{N}$ and $\mathrm{C}$, or $\mathrm{N}$ and $\mathrm{O}$, respectively. The points on the sides of the triangle labelled $\mathrm{CH}_{4}, \mathrm{H}_{2} \mathrm{O}, \mathrm{CO}_{2}$, and $\mathrm{CO}$ represent mixtures of the indicated gas with $\mathrm{N}_{2}$. The contours are labelled with the logarithms to base 10 of the production rates expressed in molecules $\mathrm{J}^{-1}$. 
small amount of $\mathrm{H}_{2} \mathrm{O}$, most $\mathrm{O}$ is bound to $\mathrm{C}$, inhibiting $\mathrm{NO}$ formation, but permitting excess $\mathrm{C}$ to enter $\mathrm{HCN}$. Results are insensitive to $\mathrm{H}$ because hydrogen does not as effectively bind to either $\mathrm{C}$ or $\mathrm{O}$ at high temperatures as do $\mathrm{C}$ and $\mathrm{O}$ or $\mathrm{C}$ and $\mathrm{N}$.

Since production rates are insensitive to the hydrogen content of the atmosphere for a wide range of interesting mixtures we lose little generality by presenting further results just for mixtures in which $\mathrm{H}=\mathrm{C}+\mathrm{O}$. Such mixtures would be represented on the ternary diagrams of Figure 2 by horizontal lines midway between base and apex. With $\mathrm{H}$ constrained in this way it is possible to show both HCN and NO production rates on one plot and also to indicate the range of values that result from uncertainties in our calculations. Figure 3 presents results for the atmosphere with $p\left(\mathrm{~N}_{2}\right)=0.9$ bar plotted in this way. The inverse variation of HCN and NO production rates is dramatically apparent.

Calculations for mixtures with a wide range of $\mathrm{N}_{2}$ partial pressures have shown only minor variation in the pattern of the contours on ternary diagrams or in the

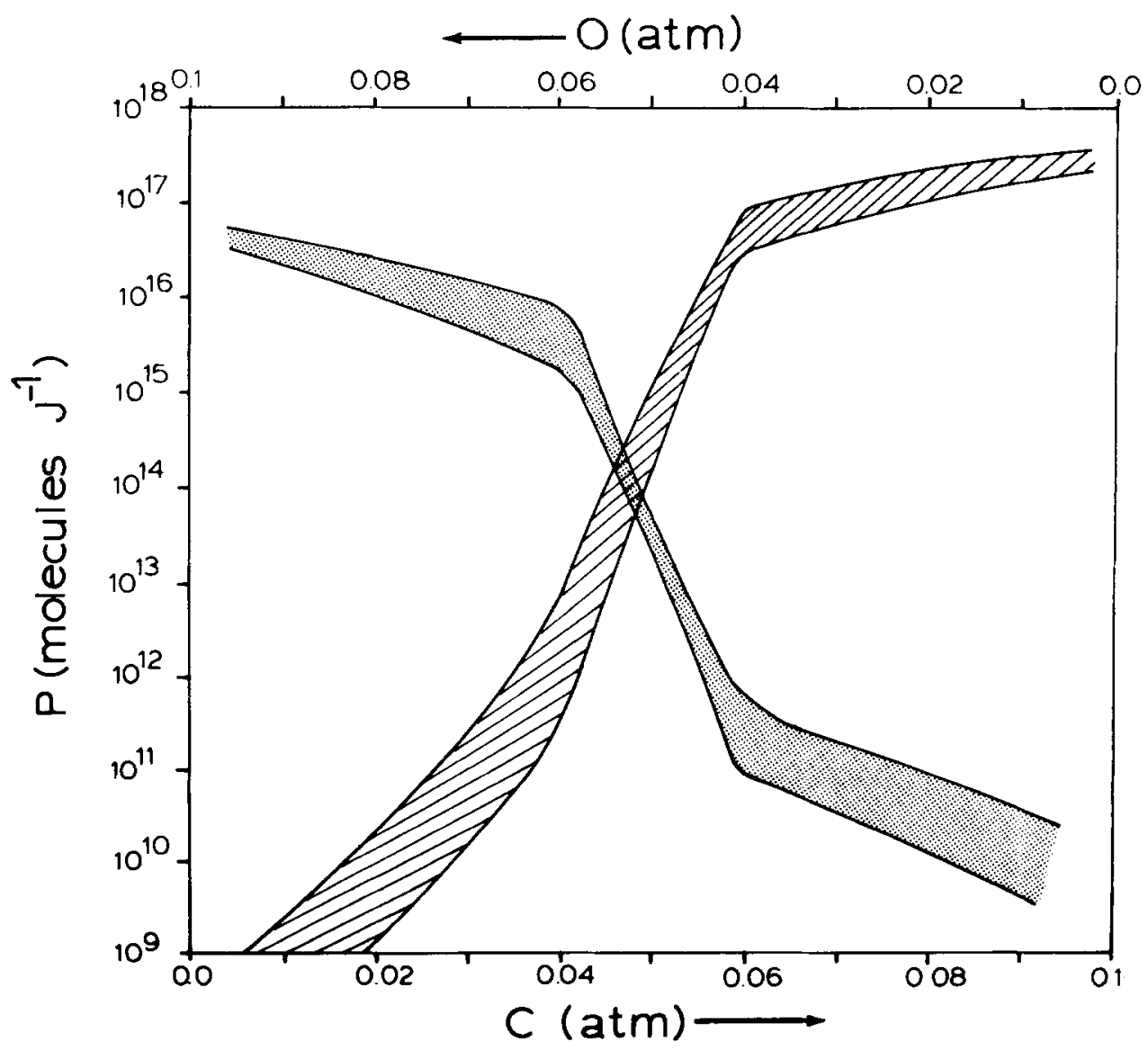

Fig. 3. The range in the calculated yields of $\mathrm{HCN}$, represented by the lined area, and NO, represented by the dotted area, for lightning with $E_{0}=10^{5} \mathrm{~J} \mathrm{~m}^{-1}, p\left(\mathrm{~N}_{2}\right)=0.9$ bar, $p\left(\mathrm{H}_{2}\right)=0.05$ bar, and $\mathrm{C}+\mathrm{O}=0.1$ bar. 
shapes of the curves in plots like Figure 3, although the values of the production rates do vary with $\mathrm{N}_{2}$ partial pressure. This variation is adequately reflected by results for mixtures with $\mathrm{H}=2 \mathrm{C}=2 \mathrm{O}$. Such results appear in Figure 4 . They show that both $\mathrm{HCN}$ and $\mathrm{NO}$ production rates decrease as the $\mathrm{N}_{2}$ mixing ratio is increased, reflecting the fact that these production rates are limited by the availability of $\mathrm{C}$ and $\mathrm{O}$, not of $N$. It is possible to combine the results in Figures 3 and 4 to obtain a rough estimate of production rates for atmospheric mixtures not illustrated. For example, Figure 3 shows an $\mathrm{HCN}$ production rate of a little more than $10^{17}$ molecules $\mathrm{J}^{-1}$ for an atmosphere containing hydrocarbons and 0.9 bar $\mathrm{N}_{2}$. Figure 4 shows that this figure would increase by almost an order of magnitude if the $\mathrm{N}_{2}$ mixing ratio were reduced to 0.5 .

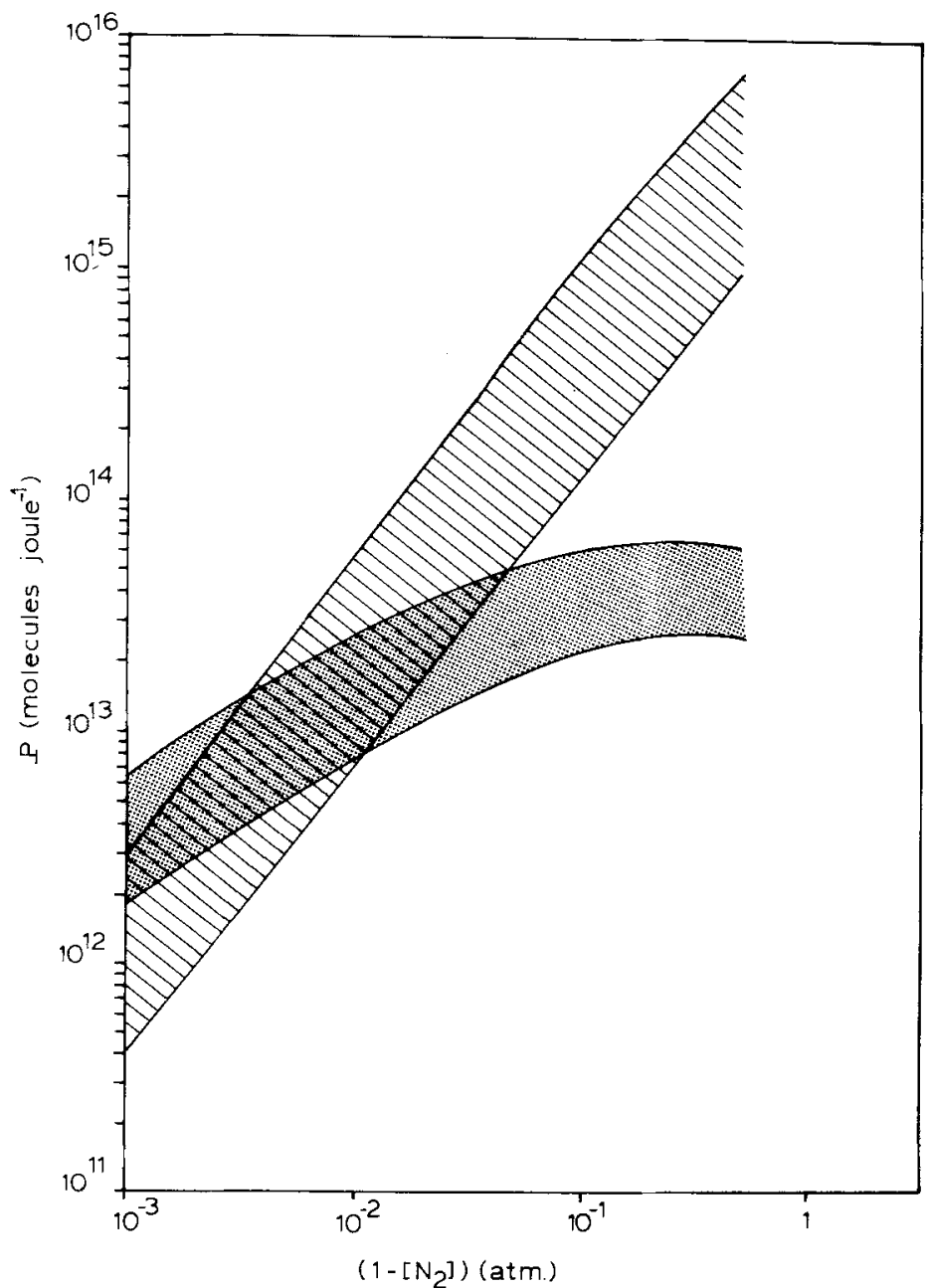

Fig. 4. The range in the calculated yields of $\mathrm{HCN}$, represented by the lined area, and NO, represented by the dotted area, for lightning with $E_{0}=10^{5} \mathrm{~J} \mathrm{~m}^{-1}, \mathrm{H}=2 \mathrm{C}=2 \mathrm{O}$, and $\mathrm{N}+\mathrm{H}+\mathrm{C}+\mathrm{O}=2$ bar. 


\section{Discussion}

Our results are consistent with previous findings that the $\mathrm{HCN}$ production rate in highly reduced atmospheres is $10^{16}$ to $10^{17}$ molecules $\mathrm{J}^{-1}$ [20-22] and that the NO production rate in the oxidizing atmosphere of today is also $10^{16}$ to $10^{17}$ molecules $\mathrm{J}^{-1}[4,6,7,9]$. However, our calculations also shed new light on the carbon and nitrogen fixation rate for intermediately reducing atmospheres, clearly indicating a rapid variation as the oxidation state of carbon varies from $\mathrm{CH}_{4}$ to $\mathrm{CO}$ to $\mathrm{CO}_{2}$. Furthermore, as discussed below, our results emphasize the need to study processes that determined the $\mathrm{CH}_{4}: \mathrm{CO}: \mathrm{CO}_{2}$ ratios in the primitive atmosphere, as it is likely that these processes ultimately controlled the rate of $\mathrm{HCN}$ and $\mathrm{NO}$ production by lightning and other high temperature processes (such as meteorite bombardment). It would appear, however, that questions concerning the $\mathrm{H}_{2}$ content of the pre-biologic atmosphere and whether nitrogen was present as $\mathrm{N}_{2}$ or $\mathrm{NH}_{3}$ are not of central importance to understanding carbon and nitrogen fixation by lightning and its impact upon chemical and biological evolution.

To convert production rates per joule into global values we use an estimate of the modern rate of dissipation of energy by lightning, $5 \times 10^{10} \mathrm{~W}[15,35]$. (However, the yields we have presented in the previous section may be used in a straightforward manner to obtain global fixation rates for any other dissipation rate, assumed or calculated). This dissipation rate would have yielded an $\mathrm{HCN}$ production rate in a primitive atmosphere rich in hydrocarbons of about $10^{35}$ molecules $\mathrm{yr}^{-1}$. While this fixation rate, assuming no destruction of $\mathrm{HCN}$, would have rapidly led to an oceanic $\mathrm{HCN}$ abundance in excess of $0.01 M$ (a concentration conducive to the formation of amino acids [20]), it would have also depleted the atmosphere's reservoir of carbon and nitrogen within about $10^{9} \mathrm{yr}$ in the absence of an abiotic source of $\mathrm{N}_{2}$ and $\mathrm{CH}_{4}$. By comparison, if carbon in the primitive atmosphere was principally $\mathrm{CO}$ [2], the HCN production rate would have been about $10^{32}$ molecules $\mathrm{yr}^{-1}$, a rate which could have produced an oceanic $\mathrm{HCN}$ abundance of about $0.01 \mathrm{M}$ in $6 \times 10^{6} \mathrm{yr}$, but would not have significantly impacted the atmosphere's composition over a time scale of billions of years. For an atmosphere rich in $\mathrm{CO}_{2}, \mathrm{HCN}$ production would have been only about $10^{27}$ molecules $\mathrm{yr}^{-1}$, which could have yielded an HCN concentration in the ocean of at most about $10^{-9} \mathrm{M}$ after 1 billion years. It would appear that in an atmosphere with a greater abundance of oxygen than carbon, such as the $\mathrm{CO}_{2}$ atmosphere favored by Walker [3], HCN production rates from lightning are an inadequate abiotic source of organic material for the evolution of life, assuming that the initial stages took place in the oceans. Furthermore, there is a possibility that lightning significantly impacted the atmospheric composition; this possibility and its ultimate impact upon chemical evolution needs to be further investigated with a coupled model of the primitive atmosphere and lightning fixation processes.

It should be pointed out that other processes besides lightning could have supplied the precursor material for the evolution of life. In an atmosphere with more $\mathrm{C}$ than $\mathrm{O}$, photochemical reactions could have been significant sources. Although laboratory 
experiments by Bar Nun et al. [22] in hydrocarbon-rich environments suggest that electrical discharges are more efficient than ultraviolet radiation, detailed photochemical models are needed. to concretely establish this fact. In a $\mathrm{CO}_{2}$ atmosphere, organic material may have been formed from photoactivated reactions, such as the reduction of $\mathrm{CO}_{2}$ by ferrous ion in the primitive ocean and various heterogeneous reactions recently identified in laboratory studies [23-28]. Whether these latter processes could have been adequate sources of organic molecules depends upon their kinetic characteristics, which have yet to be established.

Lightning on the primitive earth could have produced NO at a rate varying between $10^{34}$ molecules $\mathrm{yr}^{-1}$ for an atmosphere rich in $\mathrm{CO}_{2}$ and less than $10^{29}$ molecules $\mathrm{yr}^{-1}$ for an atmosphere rich in $\mathrm{CH}_{4}$. In the latter atmosphere, of course, more $\mathrm{N}$ is fixed as HCN. The modern rate of biological fixation of $\mathrm{N}$ in the ocean is $10^{35}$ to $10^{36}$ $\mathrm{N}$ atoms $\mathrm{yr}^{-1}$ [29], so abiotic fixation by lightning is potentially significant. Some studies suggest that much NO would have been photochemically destroyed in the atmosphere before it reached the ocean and that the ocean might have reduced such $\mathrm{NO}$ as dissolved in it [30,31], so our results for $\mathrm{N}$ fixation cannot be directly applied to discussions of selection pressures in early biological evolution [32, 33].

\section{Acknowledgement}

This work was supported in past by The National Aeronautics and Space Administration under Grant NAG-1-85 (No. WLC) and NAG W-176 (No. JGGW).

\section{References}

[1] Miller, S. L. and Urey, H. C.: 1959, Science 130, 245.

[2] Abelson, P. H.: 1966, Proc. Nat. Acad, Sci. 55, 1365.

[3] Walker, J. C. G.: 1976, in B. F. Windley (ed.), The Early History of the Earth, John Wiley, New York, pp. 535-546.

[4] Chameides, W. L.: 1979, Nature 277, 123.

[5] Noxon, J. F., 1976, Geophys. Res. Lett. 3, 463.

[6] Zipf, E. C. and Dubin, M.: 1976, Trans. Amer. Geophys. Union 57, 965.

[7] Chameides, W. L., Stedman, D. H., Dickerson, R. R., Rusch, D.W., and Cicerone, R. J.: 1977, J. Atmos. Sci. 34, 143.

[8] Tuck, A. F.: 1976, Quart. J. Roy. Meteor. Soc. 102, 749.

[9] Griffing, G. W.: 1977, J. Geophys. Res. 82, 943.

[10] Chameides, W. L.: 1979, Geophys. Res. Lett. 6, 287.

[11] Levine, J. S., Hughes, R. E., Chameides, W. L., and Howell, W. E.: 1979, Geophys. Res. Lett., $6,557$.

[12] Zel'dovich, Y. B. and Raizer, Y. P.: 1966, Physics of Shock Waves and High-Temperature Hydrodynamic Phenomena, Academic Press, New york.

[13] Lin, S. C.: 1954, J. Applied Phys. 25, 54.

[14] Zucrow, M. I. and Hoffman, J. D.: 1976, Gas Dynamics, John Wiley and Sons, New York, Vol. 1, $772 \mathrm{pp}$.

[15] Uman, M. A.: 1969, Lightning, MeGraw-Hill, New York, 264 pp.

[16] Baulch, D. L., Drysdale, D. D., Horne, D. G., and Lloyd, A. C.: 1973, Evaluated Kinetic Data for High Temperature Reactions, Vol. 2: Homogeneous Gas Phase Reactions of the $\mathrm{H}_{2}-\mathrm{N}_{2}-\mathrm{O}_{2}$ System, Chem. Rubber Co. Press, Cleveland, Ohio. 
[17] Hampson, R. F. and Garvin, D. (eds.): 1975, Chemical Kinetic and Photochemical Data for Modelling Atmospheric Chemistry, NSG Tech. Note 866, Nat. Bur. of Standards, Washington, D.C., 113 p.

[18] Duxbury, J. and Pratt, N. H.: 1974, 15th Symp. (International) on Combustion, The Combustion Institute, Pittsburgh, pp. 843-855.

[19] Stull, D. R. and Prophet, H.: 1971, JANAF Thermochemical Tables, NSRDS-NBS 37, U.S. Govt. Printing Office, Washington, D.C.

[20] Sanchez, R. A., Ferris, J. P., and Orgel, L. E.: 1967, J. Mol. Biol. 30, 223.

[21] Bar-Nun, A. and Shaviv, A.: 1975, Icarus 24, 197.

[22] Bar-Nun, A., Bar-Nun, N., Bauer, S. H. and Sagan, C.: 1970, Science 168, 470.

[23] Lasaga, A. C., Holland, H. D. and Dwyer, M. J.: 1971, Seience 174, 53.

[24] Cairns-Smith, A. G.: 1978, Nature 276, 807.

[25] Baur, M. E.: 1978, Chem. Geol. 22, 189.

[26] Halmann, M.: 1978, Nature 275, 115.

[27] Harriman, A.: 1978, Nature 276, 15.

[28] Tazuke, S. and Kitamura, N.: 1978, Nature 275, 301.

[29] Liu, S. C., Cicerone, R. J., Donahue, T. M. and Chameides, W. L.: 1977, Tellus 29, 251.

[30] Yung, Y. L. and McElroy, M. B.: 1979, Science 203, 1002.

[31] Kasting, J. F, and Walker, J. C. G.: 1981, J. Geophys. Res. 86, 1147.

[32] Margulis, L., Walker, J. C. G. and Rambler, M.: 1976, Nature 264, 620.

[33] Olson, J. M.: 1970, Science 168, 438.

[34] Kerr, R. A.: 1980, Science 210, 42.

[35] Dawson, G. A.: 1980, J. Atmos. Sci. 37, 174. 